\title{
Identification of Global Warming Contribution to the El Niño Phenomenon Using Empirical Orthogonal Function Analysis
}

\author{
Mochamad Tito Julianto', Septian Dhimas' ${ }^{1}$, Ardhasena Sopaheluwakan², Sri Nurdiati ${ }^{1}$, Pandu \\ Septiawan ${ }^{1}$ \\ ${ }^{1}$ Department of Mathematics, FMIPA Building, IPB Dramaga Campus, Bogor, Indonesia 16680 \\ ${ }^{2}$ Meteorological, Climatological, and Geophysical Agency, Kemayoran, Jakarta Pusat, DKI Jakarta, Indonesia 10610
}

\section{ARTICLE INFO}

\section{Received}

09 August 2020

\section{Revised}

08 November 2020

\section{Accepted for Publication \\ 26 January 2021}

\section{Published}

19 February 2021

doi: 10.29244/j.agromet.35.1.11-19

\section{Correspondence:}

Mochamad Tito Julianto Department of Mathematics, FMIPA Building, IPB Dramaga Campus, Bogor, Indonesia 16680 Email: mtjulianto@apps.ipb.ac.id

\footnotetext{
This is an open-access article distributed under the CC BY License. (C) 2021 The Authors. Agromet.
}

\begin{abstract}
A B S TR ACT
Sea surface temperature (SST) is identified as one of the essential climate/ocean variables. The increased SST levels worldwide is associated with global warming which is due to excessive amounts of greenhouse gases being released into the atmosphere causing the multi-decadal tendency to warmer SST. Moreover, global warming has caused more frequent extreme El Niño Southern Oscillation (ENSO) events, which are the most dominant mode in the coupled ocean-atmosphere system on an interannual time scale. The objective of this research is to calculate the contribution of global warming to the ENSO phenomenon. SST anomalies (SSTA) variability rosed from several mechanisms with differing timescales. Therefore, the Empirical Orthogonal Function in this study was used to analyze the data of Pacific Ocean sea surface temperature anomaly. By using EOF analysis, the pattern in data such as precipitation and drought pattern can be obtained. The result of this research showed that the most dominant EOF mode reveals the time series pattern of global warming, while the second most dominant EOF mode reveals the El Niño Southern Oscillation (ENSO). The modes from this EOF method have good performance with $95.8 \%$ accuracy rate.
\end{abstract}

KEYWORDS

El Niño, empirical orthogonal function, Pacific Ocean, sea surface temperature

\section{INTRODUCTION}

Sea surface temperature (SST) is a fundamental variable for understanding, monitoring and predicting fluxes of heat (Kumar et al., 2017; Liu et al., 2020), momentum and gases at a variety of scales that determine complex interactions between the atmosphere and ocean (Feng et al., 2018; O'Carroll et al., 2019). It is identified as one of the essential ocean variables (Farhan et al., 2020; Merchant et al., 2019; Miranda Espinosa et al., 2020), which is also an important parameter in climate change analysis (Carella et al., 2018; Hidayati and Chrisendo, 2010; Sakalli and Başusta, 2018). Data from the US National Oceanic and Atmospheric Administration (NOAA) showed that the average global sea surface temperature, which is the temperature of upper few meters of the ocean, has increased by approximately $0.13^{\circ} \mathrm{C}$ per decade over the past 100 years (NOAA, 2016). The primary cause of increasing SST levels worldwide is global warming, a multi-decadal tendency to warmer SST, resulted from excessive amounts of greenhouse gases being released into the atmosphere (Alawad et al., 2020; Iz, 2018; Turkington et al., 2019). Therefore, quantifying global trends and variability of SST is important to understand changes in the Earth's climate (Bulgin et al., 2020; Estiningtyas et al., 2005).

El Niño-Southern Oscillation (ENSO) is the most dominant mode in the coupled ocean-atmosphere system on an interannual time scale (Hidayat and Ando, 
2014; Wang et al., 2017; Yang et al., 2018). According to Yeh et al. (2018), ENSO cycle is a scientific term that describes the fluctuations in temperature between the ocean and atmosphere in the east-central Equatorial Pacific (approximately between the International Date Line and 120 degrees West). El Niño is referred to as the warm phase of ENSO, while La Nina as the cold phase of ENSO. Both of the warm (El Niño) and cold (La Nina) phases of ENSO exert a large impact on the global climate (Dogar et al., 2017; Guo et al., 2017; Lin and Qian, 2019; Yang et al., 2018). The intensity change of El Niño under increased greenhouse warming is a great societal concern (Cai et al., 2018), but researchers have a low confidence in the ability to predict how the phenomenon of the warm earth affects the El Niño phenomenon precisely (NOAA, 2016).

One study showed that since the late 1970s, climate change shifted the El Niño onset location from the eastern Pacific to the western Pacific and caused more frequent extreme El Niño events (Wang et al., 2019). Continued warming over the western Pacific warm pool promises conditions that will trigger more extreme events in the future (Cai et al., 2015; Hermawan, 2009; Wang et al., 2020). Therefore, this research is intended to examine the relationship between those two phenomena by analyzing sea surface temperature anomaly data in the Pacific Ocean.

SST anomalies (SSTA) variability arises from several mechanisms with differing timescales (Jüling et al., 2020; Wu et al., 2016). Interannual SSTA variability at a given location tends to be greater for some months of the year than the other (Martono, 2016), and this annual phasing of interannual variability, in turn, differs from place to place (Bulgin et al., 2020; Li et al., 2019; Saurral et al., 2018). The Empirical Orthogonal Function (EOF) method is used to analyze the dominant variability from anomaly data of sea surface temperature in the Pacific Ocean. According to Kim et al., (2015), the main purpose of this method is to reduce a large number of variability in the observed data to as few as possible, but without much reducing the spatial and temporal variability that can be explained or described.

The purpose of this research is to identify patterns that indicate global warming phenomenon, characterized by the output of the EOF method in the form of time series trend of temporal patterns and calculate their contribution to the El Niño phenomenon. In addition to providing an overview of the application of the EOF method to a spatial and temporal dataset, the benefit of this research is also understanding to what extent the global warming contributes to the $\mathrm{El}$ Niño phenomenon.

\section{RESEARCH METHODS}

\section{Data Resources}

The Hadley Center Global Sea Ice and Sea Surface Temperature (HadISST) data that was used in this research consists of time vector variables with dimension of $1,763 \times 1,180 \times 1$ of latitude vector, $360 \times 1$ of longitude vector, and $360 \times 180 \times 1,763$ of sea surface temperature data matrix. HadISST data can be downloaded on the official website of the Met Office Hadley Center. SST data in the study is limited to the Pacific Ocean region from January 1870 to November 2016 or equal to 1,763 months. To extract the data stored in NetCDF format, we utilized GNU Octave software with NetCDF interface package. After the data extraction, the SST anomaly data was formed from the HadISST data. We also need Statistics package from Octave Programming to deal with "NaN" (not a number) data values.

\section{Data Processing}

Empirical Orthogonal Function (EOF) is a method that decomposes data into mutually independent patterns recorded on data (Shore et al., 2018). EOF analysis decomposes the data into two main components, including the form $\psi_{n}(x, y)$ representing the spatial part, and $\tau_{n}(t)$ representing the temporal part. The general form of the data matrix $X$ can be expressed by Equation (1).

$$
X(x, y, t)=\sum_{n=1}^{N} \psi_{n}(x, y) \cdot \tau_{n}(t)
$$

Following the analysis steps carried out by Hannachi (2004), the initial stage of the EOF analysis was converting the anomaly data matrix from three dimensions to two dimensions. At this stage, the spatial dimensions were merged, where the rows of the new anomaly matrix are the combined spatial dimensions, and the columns are the temporal dimensions. The new matrix of anomaly data for this research has a size of 29,141 (spatial) $\times 1,763$ (months). The long-term average from the data was removed by subtracting each of the data by the mean of the matrix.

The covariance of the matrix data $X$ is defined by Equation (2).

$$
M=\frac{1}{n-1} X^{T} X
$$

which contains covariance between data grids. Then, by using the characteristic equation $|Z-\lambda I|=0$, a total of 1,763 eigenvalues are obtained along with 1,763 eigenvectors, which are orthonormal vectors. After the covariance matrix along with its eigenvalues and eigenvectors were obtained, the next step was to determine the EOF mode. As explained by Hannachi (2004), the $k^{\text {th }}$ EOF time series pattern is simply the $k^{\text {th }}$ eigenvector of the $Z$ covariance matrix, which 
corresponds to the $k^{\text {th }}$ sorted eigenvalues, from large to small eigenvalues. As the results, the EOF-1 time series is an eigenvector that corresponds to the largest eigenvalue, the EOF-2 time series corresponds to the second largest eigenvalue and so on for other EOF time series. The $i^{\text {th }}$ spatial pattern can be obtained from the anomaly data projection on the $i$ th EOF time series pattern by using the Equation (3).

$$
\psi_{i}(\text { spatial })=\operatorname{anomaly}(\text { spatial }, t) \cdot \tau_{i, k}(t)
$$

where the anomaly is the ocean surface temperature anomaly data for the Pacific Ocean, $\psi_{i}$ is $i^{\text {th }}$ spatial pattern of EOF, and $\tau_{i, k}$ is the $k^{\text {th }}$ EOF time series in the k-month with $i, k=1,2, \ldots, 1,763$.

The purpose of the EOF method is to identify a linear combination of all variables in data grid, which explains the maximum variance. It was used to determine direction $a=\left(a_{1}, a_{2}, \ldots, a_{p}\right)^{T}$, thus $X a$ has maximum variability. The variance of $X a$ is determined by using Equation (4).

$$
\operatorname{var}(X a)=\frac{1}{n-1}\|X a\|^{2}=\frac{1}{n-1}(X a)^{T}(X a)=a^{T} M a(4)
$$

To generate a confined problem, it is commonly required $a$ vector to be a unit vector, so that the problem form has constraints (Equation 5 and 6).

$$
\max _{a}\left(a^{T} M a\right)
$$

where $a^{T} a=1$. The solution to the problem is a simple eigenproblem.

$$
M a=\lambda a
$$

By the definition, the covariance matrix $M$ in the equation is a symmetrical diagonalizable matrix. The $k^{\text {th }}$ EOF time series pattern is simply the $k^{\text {th }}$ eigenvector from covariance matrix $M$, which corresponds to the $k^{\text {th }}$ eigenvalue of decreasing ordered eigenvalues. Eigenvalue $\lambda_{k}$, which corresponds to the $k^{\text {th }}$ EOF mode, gives a measure of the explanatory variance of the $k^{\text {th }}$ eigenvector with $k$ equals to $1, \ldots, N$. Variability that can be explained in this study will henceforth be called the contribution of the $k^{\text {th }}$ EOF mode (EOF- $k$ ) to observed data variability and generally written in percentages (Equation 7).

$$
\text { Contribution of EOF } k=\frac{\lambda_{k}}{\sum_{k=1}^{N} \lambda_{k}} \times 100 \%
$$

The final step was to measure how well the EOF mode approaches the observed data. The error is calculated using the Mean Squared Error method. According to Roberts and Vandenplas (2017), Mean Squared Error (MSE) is an estimator that measures the average of the squared errors or deviations. MSE is a measure of the quality of the estimator whose value is always non-negative and the value, which gets closer to zero, means the better estimator. Besides being used for an unbiased estimator, the MSE value is a variance of the estimator as well. The MSE value can be estimated using Equation (8).

$$
M S E=\frac{1}{n} \sum_{i=1}^{n}\left(\widehat{Y}_{l}-Y_{i}\right)^{2}
$$

where the $\hat{Y}$ is a vector of $n$ predictors, and $Y$ is a vector of the observed data.

\section{RESULTS AND DISCUSSIONS}

This research used monthly SST anomaly data of the Pacific Ocean region from January 1870 to November 2016. The covariance matrix was obtained by finding the intertime covariance of the anomaly matrix, so it has a size of $1,763 \times 1,763$. Therefore, the results obtained are 1,763 eigenvalues along with 1,763 eigenvectors, where all eigenvectors are orthonormal vectors. A total of four EOF modes corresponding to the 4 largest eigenvalues were analyzed regarding their contribution to all data variability.

Each EOF mode has contributed to the variability of anomaly data, and the total contribution of all EOF modes is $100 \%$. EOF-1 mode was able to contribute to anomaly data variability for $33.23 \%$, EOF2 mode for $17.63 \%$, EOF- 3 mode for $4.72 \%$, and EOF- 4 mode with a contribution of $4.06 \%$. Modes are independent of each other, so that the EOF-k mode (for $k>1$ ) is able to contribute to the variability of temperature anomaly data outside the contribution of the EOF-1 mode. The cumulative contribution of the four most dominant modes is $59.64 \%$.

Values in the EOF time series pattern represent anomaly proportions relative to the average. Negative values in the time series indicate that at that time sea surface temperatures are below long term average from the data, while positive values indicate that sea surface temperatures are above the long term average.

Figure 1 shows the time series plot of the $1^{\text {st }}, 2^{\text {nd }}$, $3^{\text {rd }}$, and $4^{\text {th }}$ EOF modes with the largest contribution to the variability of Pacific Ocean surface temperature anomaly data. EOF-1 mode contributes for $33.23 \%$ to the data, followed by EOF-2, EOF-3, and EOF- 4 which contributes consecutively for $17.63 \%, 4.72 \%$, and $4.06 \%$ to the data. The figure shows phenomena that occurred in the Pacific Ocean. The horizontal axis represents the year, while the vertical axis represents the amplitude of the proportion of anomalous temperature relative to average. The EOF-1 mode time series values tend to increase annually. This mode is argued to strongly indicate an increased temperature in the Pacific Ocean. In other words, the warming in this mode indicates the phenomenon of global warming in the Pacific Ocean.

The values in the EOF spatial pattern have no dimensions. The spatial pattern in EOF-1 mode corresponds to the time series of EOF-1 mode, meaning 

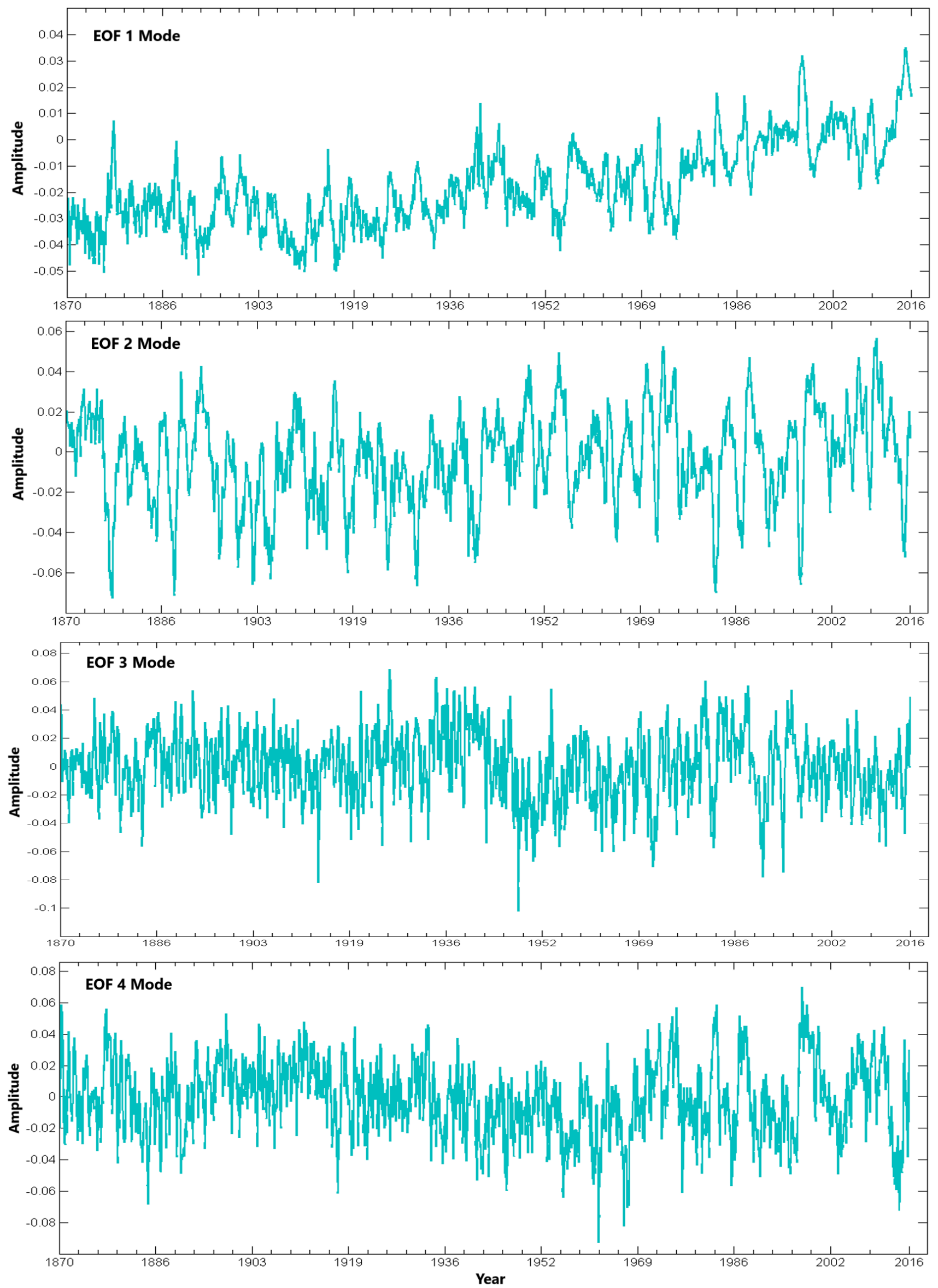

Figure 1. Time series plot of Pacific Ocean's $\left(60^{\circ} \mathrm{S}-60^{\circ} \mathrm{N}\right.$ and $\left.110^{\circ} \mathrm{E}-70^{\circ} \mathrm{W}\right)$ surface temperature anomaly in terms of EOF-1, EOF-2, EOF-3, and EOF-4 Mode based on Hadley Center Global Sea Ice and Sea Surface Temperature data. 
that the spatial pattern and time series of EOF-1 mode illustrate the same phenomenon, and so do the other modes. Spatial patterns describe the coordinates of the temperature anomaly variability.

The EOF-1 spatial pattern plot (see Figure 2) corresponds to a time series pattern that indicates the phenomenon of global warming. A positive value indicates that the coordinates are directly proportional to the time series pattern, and the inverse is for a negative value. In spatial distribution for EOF-1 mode, it is quite clearly shown that the value of positive variability is evenly distributed, meaning that the phenomenon of global warming occurs evenly throughout the Pacific Ocean region. The high positive variability values were also observed in the NINO3.4 region $\left(5^{\circ} \mathrm{S}-5^{\circ} \mathrm{N}\right.$ and $170^{\circ} \mathrm{W}-120^{\circ} \mathrm{W}$ ) that is shown by the red box at several scattered points.

The EOF-2 spatial pattern plot corresponds to the EOF-2 mode time series. Unlike the previous result, the EOF-2 spatial pattern shows that there is high variability in the NINO3.4 region. This spatial pattern indicates El Niño phenomena commonly called El NiñoSouthern Oscillation (ENSO) that occurred from Pacific SST analysis. The colour indicates negative values, meaning that the NINO3.4 region in the spatial pattern has a negative relation with the temporal pattern of the
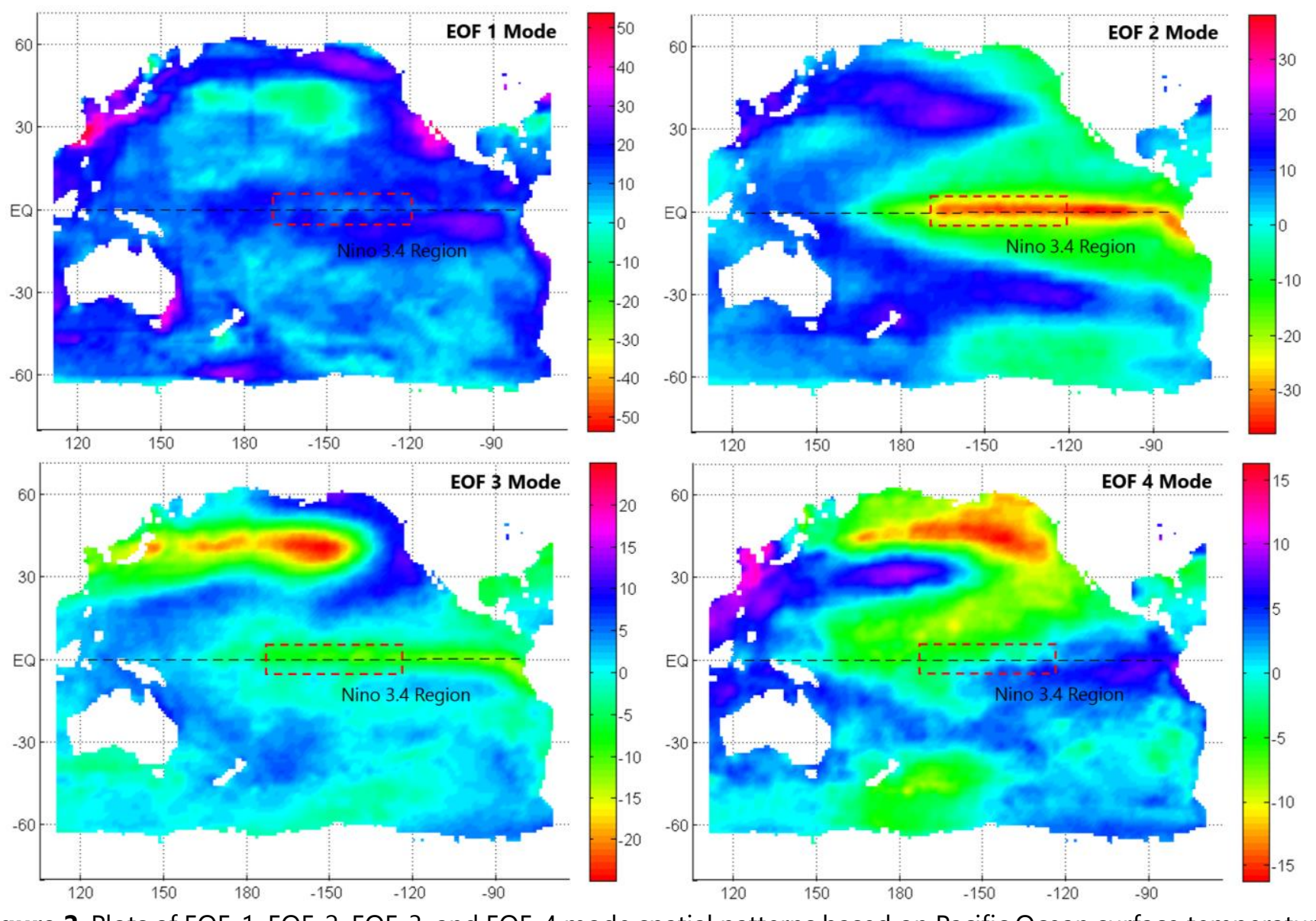

Figure 2. Plots of EOF-1, EOF-2, EOF-3, and EOF-4 mode spatial patterns based on Pacific Ocean surface temperature anomaly data.

EOF-2 mode. Therefore, the NINO3.4 index can be build by using temporal pattern EOF-2 mode. The comparison between EOF-2 mode temporal pattern with the ENSO index will be explained later in this research.

The spatial pattern of both EOF-3 and EOF-4 modes show high variability in temperature anomaly data in the northern area of the Pacific with a negative value. On the contrary, in the NINO3.4 region, the variability of the spatial pattern is relatively low compared to other areas. The contribution of EOF-3 and EOF-4 mode is also relatively small in comparison to the total contribution of EOF-1 and EOF-2 mode. Moreover, EOF-3 and EOF-4 mode illustrate different phenomenon from El Niño. Therefore, the results from EOF-3 and EOF-4 mode was not analyzed further.

The next step is to see the extent of EOF-1 mode which indicates the phenomenon of global warming in the NINO3.4 region in influencing the approximation of the observed data for the NINO3.4 index using the EOF-2 mode which represents the NINO3.4 index. NINO3.4 index is one of several ENSO indicators based on sea surface temperatures. NINO3.4 index is the average of sea surface temperature anomaly in the coordinate of $5^{\circ} \mathrm{N}$ to $5^{\circ} \mathrm{S}$ and $170^{\circ} \mathrm{W}$ to $120^{\circ} \mathrm{W}$.

\section{.}


Figure 3 shows NINO3.4 index approximation using EOF-2 mode (top) and both EOF-1 and EOF-2 combined (bottom) with the NINO3.4 index that is shown by $N_{k}$. From Figure 3 (bottom), we argue that the visual mode of EOF-1 $\left(\widehat{N}_{1, k}\right)$ have a considerable contribution to the observed data $\left(N_{k}\right)$ approximation. Combining both modes make the approximation more precise in resemblance to the observed data $\left(N_{k}\right)$. To measure how well the EOF mode approaches the observed data, the error is calculated using the Mean Squared Error method. The error between the NINO3.4 index $\left(N_{k}\right)$ and EOF-2 mode that is shown in Figure 3 (top) is $61.62 \%$. Meanwhile, the error between the observed data and the sum of EOF- 1 and EOF- 2 is $4.2 \%$, which is much smaller than before.

From this result, we suggested that the global warming signal, which is indicated by EOF-1 mode, has a significant contribution to the El Niño phenomenon. This is also reinforced by the error calculation of NINO3.4 index approximation that has a much smaller error when incorporating the global warming signal $\left(\widehat{N}_{1, k}\right)$ to the approximation. Figure 4 shows a plot of the time series of EOF-1 mode $\left(\widehat{N}_{1, k}\right)$ that indicates the global warming phenomenon occurred in the NINO3.4 region. The variability of EOF-1 mode to the NINO3.4 index from January 1870 to November 2016 is calculated based on the difference between the highest and the lowest temperature anomaly and is equal to $1.36^{\circ} \mathrm{C}$. This value was generated by multiplying the average value of the temperature anomaly in the NINO3.4 region in EOF-1 spatial pattern by 0.9 , which is the range of the value in EOF-1 time series. The average value of the temperature anomaly in the NINO3.4 region obtained from the spatial pattern is $15.07^{\circ} \mathrm{C}$.

By using the same concept, the contribution of EOF-1 mode $\left(\widehat{N}_{1}\right)$ to the NINO3.4 region was calculated based on the difference in amplitude of trend from January 1870 to November 2016, then multiplied by the average value of the NINO3.4 region in EOF-1 mode spatial pattern. The difference of amplitude of trend in temporal mode is $0.051^{\circ} \mathrm{C}$ and the average value of EOF-1 mode spatial pattern is $14.85^{\circ} \mathrm{C}$, so the result is $0.76^{\circ} \mathrm{C}$. Therefore, we suggest that EOF-1 mode indicated global warming signal which contributes $0.76^{\circ} \mathrm{C}$ to the warming rate of the NINO3.4 region.
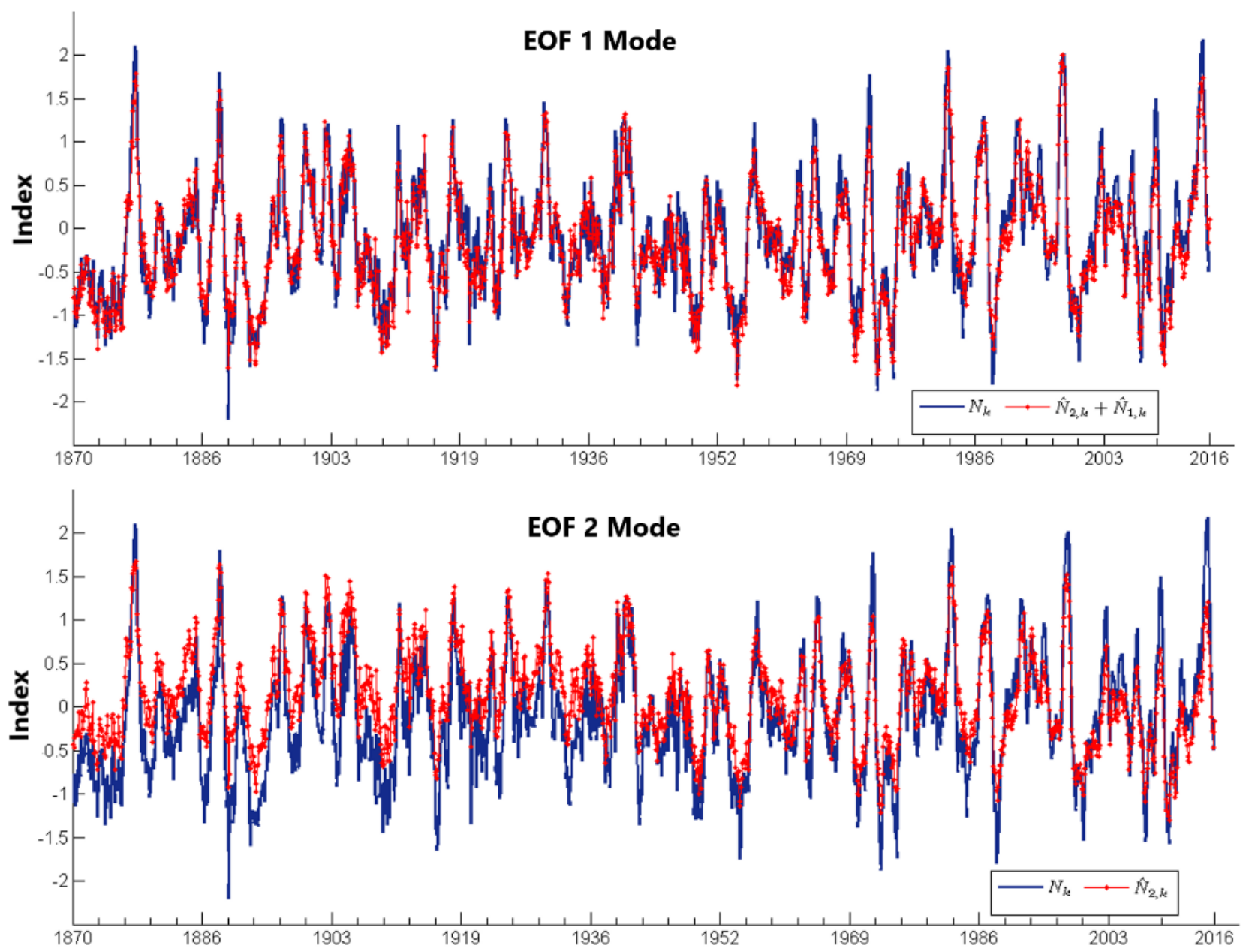

Figure 3. The plot of the observed data for the NINO3.4 index $\left(N_{k}\right)$, the EOF-2 mode which represents the NINO3.4 index $\left(\widehat{N}_{2, k}\right)$ and the combined EOF-2 mode which represents the NINO3.4 index with the EOF-1 mode which indicates the occurrence of global warming $\left(\widehat{N}_{2, k}+\widehat{N}_{1, k}\right)$. 


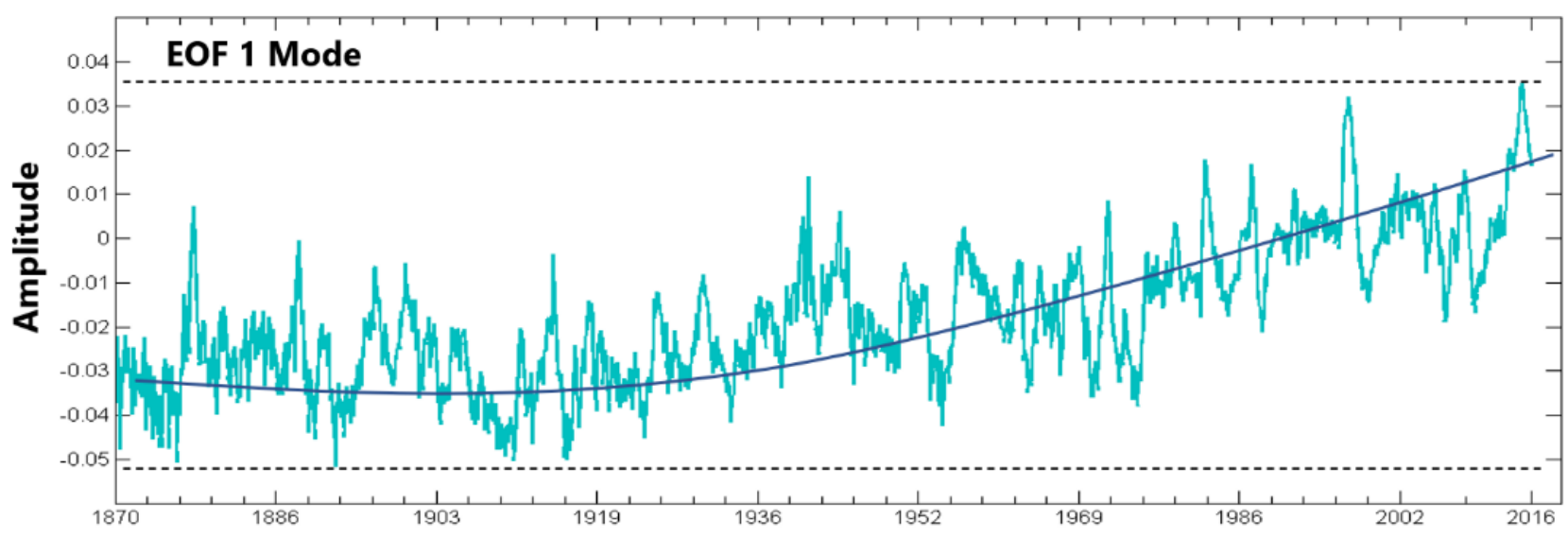

Figure 4. Contribution of the EOF-1 mode which indicates the occurrence of global warming in the NINO3.4 region $\left(\widehat{N}_{1, k}\right)$.

A previous research revealed that the response of ENSO thermodynamics and its contribution to ENSO amplitude change under global warming have not been fully understood (Zheng, 2019). However, there is a clear warming trend in the tropical SST temperatures that has an effect on the borderline ENSO cases, such as in 2016 (Turkington et al., 2019). The prolonged El Nino lifetime mainly applied to extreme El Niño events, which was caused by earlier outbreak of the westerly wind bursts, shallower climatological thermocline depth and weaker "discharge" rate of the ENSO warm signal in response to global warming (Sun et al., 2017).

\section{CONCLUSIONS}

The Empirical Orthogonal Function method applied to the sea surface temperature anomaly dataset of the Pacific Ocean is able to decompose both temporal and spatial patterns. It was admitted that the two most dominant modes contributed to sea surface temperature anomaly data in the Pacific Ocean region are EOF-1 and EOF-2 mode, with the contribution of each mode consecutively $33.23 \%$ and $17.63 \%$ to the data.

The most dominant EOF (EOF-1) mode indicates the global warming pattern, where the time series pattern shows a value that tends to increase, and the spatial pattern shows that the global warming phenomenon occurs evenly in almost all regions of the Pacific Ocean. In the second most dominant EOF mode (EOF-2), its spatial pattern describes high variability in the El Niño region, thus indicating that this second mode describes the pattern of ENSO (El Niño-Southern Oscillation).

By deriving the general form of the EOF method obtained for the NINO3.4 region, it is also concluded that the EOF mode indicating the occurrence of global warming phenomenon directly affects the magnitude of the NINO3.4 index, or in other words, directly affects the occurrence of the El Niño phenomenon. During the observation period in this study, the EOF mode contributed to the variability of NINO3.4 region temperature for $1.36^{\circ} \mathrm{C}$, while the NINO3.4 region has a trend of warming rate of $0.76^{\circ} \mathrm{C}$. By utilizing the two EOF modes from 1,763 modes available, we can approximate the observed data of the NINO3.4 index with $4.2 \%$ error.

\section{ACKNOWLEDGEMENT}

The authors would like to thank Department of Mathematics, IPB University and Meteorological, Climatological and Geophysical Agency (BMKG) for their invaluable support and assistance throughout this research.

\section{REFERENCES}

Alawad, K.A., Al-Subhi, A.M., Alsaafani, M.A., Alraddadi, T.M., 2020. Decadal variability and recent summer warming amplification of the sea surface temperature in the Red Sea. PLOS ONE 15 ,

$\mathrm{e} 0237436$. https://doi.org/10.1371/journal.pone.0237436

Bulgin, C.E., Merchant, C.J., Ferreira, D., 2020. Tendencies, variability and persistence of sea surface temperature anomalies. Scientific Reports 10, 7986. https://doi.org/10.1038/s41598-020-64785-9

Cai, W., Santoso, A., Wang, G., Yeh, S.-W., An, S.-I., Cobb, K.M., Collins, M., Guilyardi, E., Jin, F.-F., Kug, J.S., Lengaigne, M., McPhaden, M.J., Takahashi, K., Timmermann, A., Vecchi, G., Watanabe, M., Wu, L., 2015. ENSO and greenhouse warming. Nature Clim. Change 5, 849-859. https://doi.org/10.1038/nclimate2743

Cai, W., Wang, G., Dewitte, B., Wu, L., Santoso, A., Takahashi, K., Yang, Y., Carréric, A., McPhaden, M.J., 2018. Increased variability of eastern 
Pacific El Niño under greenhouse warming. Nature 564, 201-206. https://doi.org/10.1038/s41586-018-0776-9

Carella, G., Kennedy, J.J., Berry, D.I., Hirahara, S., Merchant, C.J., Morak-Bozzo, S., Kent, E.C., 2018. Estimating Sea Surface Temperature Measurement Methods Using Characteristic Differences in the Diurnal Cycle. Geophysical Research Letters 45, 363-371. https://doi.org/10.1002/2017GL076475

Dogar, M.M., Kucharski, F., Azharuddin, S., 2017. Study of the global and regional climatic impacts of ENSO magnitude using SPEEDY AGCM. Journal of Earth System Science 126, 30. https://doi.org/10.1007/s12040-017-0804-4

Estiningtyas, W., Suciantini, Irianto, G., 2005. Prediksi Curah Hujan Bulanan Berdasarkan Suhu Permukaan Laut Nino 3.4: suatu Pendekatan dengan Metode Filter Kalman (monthly Rainfall Prediction Based On Sea Surface Temperature Nino 3.4: The Approach With Kalman Filtering). Agromet 19, 43-56. https://doi.org/10.29244/j.agromet.19.2.43-56

Farhan, A., Ilhamsyah, Y., Akhyar, 2020. The Use of SST Anomaly to Predict Seasonal Rainfall during the Second Planting Period in the Tanoh Abee Irrigation Area, Aceh Besar. Agromet 34, 100109.

https://doi.org/10.29244/j.agromet.34.2.100109

Feng, X., Haines, K., de Boisséson, E., 2018. Coupling of surface air and sea surface temperatures in the CERA-20C reanalysis. Quarterly Journal of the Royal Meteorological Society 144, 195-207. https://doi.org/10.1002/qj.3194

Guo, Y., Ting, M., Wen, Z., Lee, D.E., 2017. Distinct Patterns of Tropical Pacific SST Anomaly and Their Impacts on North American Climate. Journal of Climate 30, 5221-5241. https://doi.org/10.1175/JCLI-D-16-0488.1

Hannachi, A., 2004. A primer for EOF analysis of climate data. Department of Meteorology, University of Reading 1-33.

Hermawan, E., 2009. Climate Projection Over Indonesia Based on the Total Fossil Fuel Co2 Emission Prediction Using the Box-jenkins Arima Model. Agromet 23, 1-10 https://doi.org/10.29244/j.agromet.23.1.1-10

Hidayat, R., Ando, K., 2014. Variabilitas Curah Hujan Indonesia dan Hubungannya dengan ENSO/IOD: Estimasi Menggunakan Data JRA25/JCDAS. Agromet 28, 1-8. https://doi.org/10.29244/j.agromet.28.1.1-8
Hidayati, R., Chrisendo, D.N., 2010. Prediction of Planting Date and Growing Period using Sea Surface Temperature (SST) Anomalies in Nino 3.4 for Indramayu District. Agromet 24, 1-8. https://doi.org/10.29244/j.agromet.24.2.1-8

Iz, H.B., 2018. Is the global sea surface temperature rise accelerating? Geodesy and Geodynamics 9, 432-438. https://doi.org/10.1016/j.geog.2018.04.002

Jüling, A., Dijkstra, H.A., Hogg, A.M.C., Moon, W., 2020. Multidecadal variability in the climate system: phenomena and mechanisms, European Physical Journal Plus. https://doi.org/10.1140/epjp/s13360-02000515-4

Kim, K.-Y., Hamlington, B., Na, H., 2015. Theoretical foundation of cyclostationary EOF analysis for geophysical and climatic variables: Concepts and examples. Earth-Science Reviews 150, $201-$ 218.

https://doi.org/10.1016/j.earscirev.2015.06.003

Kumar, B.P., Cronin, M.F., Joseph, S., Ravichandran, M., Sureshkumar, N., 2017. Latent Heat Flux Sensitivity to Sea Surface Temperature: Regional Perspectives. Journal of Climate 30, 129-143. https://doi.org/10.1175/JCLI-D-160285.1

Li, Y., Han, W., Zhang, L., Wang, F., 2019. Decadal SST Variability in the Southeast Indian Ocean and Its Impact on Regional Climate. Journal of Climate 32, 6299-6318. https://doi.org/10.1175/JCLI-D-19-0180.1

Lin, J., Qian, T., 2019. A New Picture of the Global Impacts of El Nino-Southern Oscillation. Scientific Reports 9, 17543. https://doi.org/10.1038/s41598-019-54090-5

Liu, Y., Yu, L., Chen, G., 2020. Characterization of Sea Surface Temperature and Air-Sea Heat Flux Anomalies Associated With Mesoscale Eddies in the South China Sea. Journal of Geophysical Research: Oceans 125, e2019JC015470. https://doi.org/10.1029/2019JC015470

Martono, M., 2016. Seasonal and Inter Annual Variation of Sea Surface Temperature in the Indonesian Waters. Forum Geografi. https://doi.org/10.23917/forgeo.v30i2.1530

Merchant, C.J., Embury, O., Bulgin, C.E., Block, T., Corlett, G.K., Fiedler, E., Good, S.A., Mittaz, J., Rayner, N.A., Berry, D., Eastwood, S., Taylor, M., Tsushima, Y., Waterfall, A., Wilson, R., Donlon, C., 2019. Satellite-based time-series of seasurface temperature since 1981 for climate applications. Scientific Data 6, 223. https://doi.org/10.1038/s41597-019-0236-x 
Miranda Espinosa, M.T., Giuliani, G., Ray, N., 2020. Reviewing the discoverability and accessibility to data and information products linked to Essential Climate Variables. null 13, 236-252. https://doi.org/10.1080/17538947.2019.16208 82

NOAA, 2016. Climate Monitoring [WWW Document]. Global Land and Ocean: Anomaly. URL https://www.ncdc.noaa.gov/climatemonitoring/

O'Carroll, A.G., Armstrong, E.M., Beggs, H.M., Bouali, M., Casey, K.S., Corlett, G.K., Dash, P., Donlon, C.J., Gentemann, C.L., Høyer, J.L., Ignatov, A., Kabobah, K., Kachi, M., Kurihara, Y., Karagali, I., Maturi, E., Merchant, C.J., Marullo, S., Minnett, P.J., Pennybacker, M., Ramakrishnan, B., Ramsankaran, R., Santoleri, R., Sunder, S., Saux Picart, S., Vázquez-Cuervo, J., Wimmer, W., 2019. Observational Needs of Sea Surface Temperature. Frontiers in Marine Science 6, 420. https://doi.org/10.3389/fmars.2019.00420

Roberts, C., Vandenplas, C., 2017. Estimating Components of Mean Squared Error to Evaluate the Benefits of Mixing Data Collection Modes. Journal of Official Statistics 33, 303334. https://doi.org/10.1515/jos-2017-0016

Sakalli, A., Başusta, N., 2018. Sea surface temperature change in the Black Sea under climate change: A simulation of the sea surface temperature up to 2100. International Journal of Climatology 38 , 4687-4698. https://doi.org/10.1002/joc.5688

Saurral, R.I., Doblas-Reyes, F.J., García-Serrano, J., 2018. Observed modes of sea surface temperature variability in the South Pacific region. Climate Dynamics 50, 1129-1143. https://doi.org/10.1007/s00382-017-3666-1

Shore, R.M., Freeman, M.P., Gjerloev, J.W., 2018. An Empirical Orthogonal Function Reanalysis of the Northern Polar External and Induced Magnetic Field During Solar Cycle 23. Journal of Geophysical Research: Space Physics 123, 781-795. https://doi.org/10.1002/2017JA024420

Sun, X., Xia, Y., Yan, Y., Feng, W., Huang, F., Yang, X.Q., 2017. Change of ENSO characteristics in response to global warming. Presented at the AGU Fall Meeting Abstracts, pp. GC41B-1010.

Turkington, T., Timbal, B., Rahmat, R., 2019. The impact of global warming on sea surface temperature based El Niño-Southern Oscillation monitoring indices. International Journal of Climatology 39, 1092-1103. https://doi.org/10.1002/joc.5864

Wang, B., Luo, X., Yang, Y.-M., Sun, W., Cane, M.A., Cai, W., Yeh, S.-W., Liu, J., 2019. Historical change of El Niño properties sheds light on future changes of extreme El Niño. Proc Natl Acad Sci USA 116 , 22512. https://doi.org/10.1073/pnas.1911130116

Wang, C., Deser, C., Yu, J.-Y., Dinezio, P., Clement, A., 2017. El Niño and Southern Oscillation (ENSO): A review. pp. 85-106. https://doi.org/10.1007/978-94-017-7499-4_4

Wang, G., Cai, W., Santoso, A., 2020. Stronger Increase in the Frequency of Extreme Convective than Extreme Warm El Ni?o Events under Greenhouse Warming. Journal of Climate 33, 675-690. https://doi.org/10.1175/JCLI-D-190376.1

Wu, R., Lin, J., Li, B., 2016. Spatial and Temporal Variability of Sea Surface Temperature in Eastern Marginal Seas of China. Advances in Meteorology 2016, 3820720 https://doi.org/10.1155/2016/3820720

Yang, S., Li, Z., Yu, J.-Y., Hu, X., Dong, W., He, S., 2018. El Niño-Southern Oscillation and its impact in the changing climate. National Science Review 5, 840-857. https://doi.org/10.1093/nsr/nwy046

Yeh, S.-W., Cai, W., Min, S.-K., McPhaden, M.J., Dommenget, D., Dewitte, B., Collins, M., Ashok, K., An, S.-I., Yim, B.-Y., Kug, J.-S., 2018. ENSO Atmospheric Teleconnections and Their Response to Greenhouse Gas Forcing. Reviews of Geophysics 56, 185-206. https://doi.org/10.1002/2017RG000568

Zheng, X.-T., 2019. Indo-Pacific Climate Modes in Warming Climate: Consensus and Uncertainty Across Model Projections. Current Climate Change Reports 5, 308-321. https://doi.org/10.1007/s40641-019-00152-9 